\title{
Traços de Concreto sem Função Estrutural com Adição de Entulho
}

\section{Concrete Lines no Function With Structural Waste Addition}

\author{
1 Júlio Cesar Salles Cunha \\ 1 Cleidiane Lacerda \\ 2 Horácio Guimarães Delgado Júnior
}

1 Discente do Mestrado Profissional em Materiais, MEMAT - UniFOA.
2 Docente do Mestrado Profissional em Materiais, MEMAT - UniFOA.

\section{RESUMO}

A indústria da construção civil gera por ano cerca de $50 \%$ de todo resíduo sólido gerado segundo o IBGE, este estudo analisa o comportamento dos traços de concreto sem função estrutural confeccionados com estes resíduos, estes entulhos são de demolição e tem uma característica bastante peculiar, dessa forma, a caracterização média deste resíduo está condicionada a parâmetros específicos da região geradora do resíduo analisado. A degradação do meio gerada pelos resíduos de construção civil pode ocorrer pelo esgotamento de áreas sadias e poluição dos cursos d'água, contudo deve atender a uma série de resoluções, decretos, leis e portarias, como a resolução Conama ${ }^{\circ} 307$, o Estatuto das Cidades e a Lei Federal 9605 (crimes ambientais), que estabelecem diretrizes, critérios e procedimentos para a gestão de seus resíduos. 0 processo constituiu na confecção de artefatos de concreto (corpos de prova) para obtenção das respectivas resistências à compressão simples e compressão axial. Os ensaios foram realizados aos 7, 14, 21 e 28 dias de cura, sendo feita as substituições de agregados naturais (brita 1) por entulhos, cujas misturas foram nas proporções de, $15 \%, 30 \%$ e $100 \%$. Em geral, os resultados foram aceitáveis pelas normas da Associação Brasileira de Normas Técnicas - ABNT. Os resultados de validação obtidos pelo modelo foram bastante satisfatórios. Os resultados mostraram a viabilidade de confeccionar artefatos de concreto reciclando entulhos da construção civil.

\section{Palavras-chave}

Entulhos, artefatos de concreto, reciclagem.

\begin{abstract}
The construction industry generates annually about $50 \%$ of all solid waste generated according to the IBGE, this study analyzes the behavior of concrete mixtures without structural function made of these residues these spoils are demolition and has a very peculiar characteristic thus, the average characterization of this waste is subject to specific parameters of the analyzed region spanning residues. The degradation of the generated by building waste may occur by the depletion of healthy areas and pollution of water courses, but must meet a series of resolutions, decrees, laws and ordinances, as the Resolution CONAMA 307, the Status of Cities and the Federal Law 9605 (environmental crimes) that establish guidelines, criteria and procedures for the management of their waste. The process consisted in making concrete artifacts (specimens) were used to obtain resistance to compressive and axial compression. Assays were carried out at 7, 14, 21 and 28 days of curing, the substitutions being made of natural aggregates (crushed 1) by debris, which were mixed in the proportions of $15 \%, 30 \%$ and $100 \%$. In general, the results were acceptable by the standards of the Brazilian Association of Technical Standards - ABNT. The validation results obtained by the model were very satisfactory. The results showed the feasibility of making concrete artifacts recycling construction debris.
\end{abstract}

\section{Keywords}

Debris; concrete artifacts; recycling.

\section{Como você deve citar?}

Cunha, Júlio Cesar Salles; Lacerda, Cleidiane; Delgado Júnior, Horácio Guimarães. Traços de Concreto sem Função Estrutural com Adição de Entulho. Cadernos UniFOA, Volta Redonda, n. 31, p. 53-63, ago. 2016. 


\section{INTRODUÇÃO}

No campo da Construção Civil, além de sua importância dentro da economia no Brasil, sempre esteve muito vinculado a questões pertinentes a perdas e desperdícios. É verdade que o assunto não vinha sendo uma prioridade para o setor até bem pouco tempo atrás. Dessa forma, a indústria da construção civil ficou ultrapassada em relação a outros segmentos industriais quando se trata do assunto, e ainda apresenta números preocupantes em relação a perdas e desperdícios (ALBERTIN, 2011).

A extração de matérias primas para diversas utilizações, além de deteriorar a natureza, também está gerando em certas áreas desajustes ecológicos, como se pode notar na maioria das regiões de extração mineral. Também devido à necessidade de extrair algumas matérias primas, a distâncias cada vez maiores dos centros consumidores, pode inviabilizar sua utilização em algumas localidades, pelo custo do transporte (CARNEIRO ET AL., 2000).

O presente trabalho apresenta uma alternativa para a reciclagem de entulho da construção civil com aplicação direta na confecção de concreto para fins não estruturais.

\section{MATERIAIS E MÉTODOS}

O estudo pretende verificar, através de diversos ensaios de laboratório (vários traços), visando uma avaliação mais detalhada do resíduo como agregado, analisando as propriedades mecânicas dos concretos recicláveis (resistência à compressão, tração e MEV) produzidos com entulhos de obra provenientes de resíduos de construção e demolição (concreto de calçadas), visando à sua utilização como elementos não estruturais em obras de construção civil.

Desenvolver um concreto que mantém suas características (resistência a compressão e resistência a tração) essenciais a aplicação, apontar as peculiaridades utilizando resido da construção civil, reduzindo desta maneira os custos do que os tradicionais.

Todas as diretrizes analisadas e atestadas em de acordo conforme o anexo I - NBR 7215-resistência a compressão, anexo II - NBR 7222- resistência a compressão diametral, anexo III.

\subsection{Materiais}

Seleção e classificação de materiais. Os materiais utilizados para os ensaios foram:

\subsubsection{Cimento}

Para os ensaios preliminares foi utilizado o cimento CP III-40, conforme NBR 5735 (ABNT, 1991), como mostra a Figura 1. 
Figura 1 - Cimento Portland.

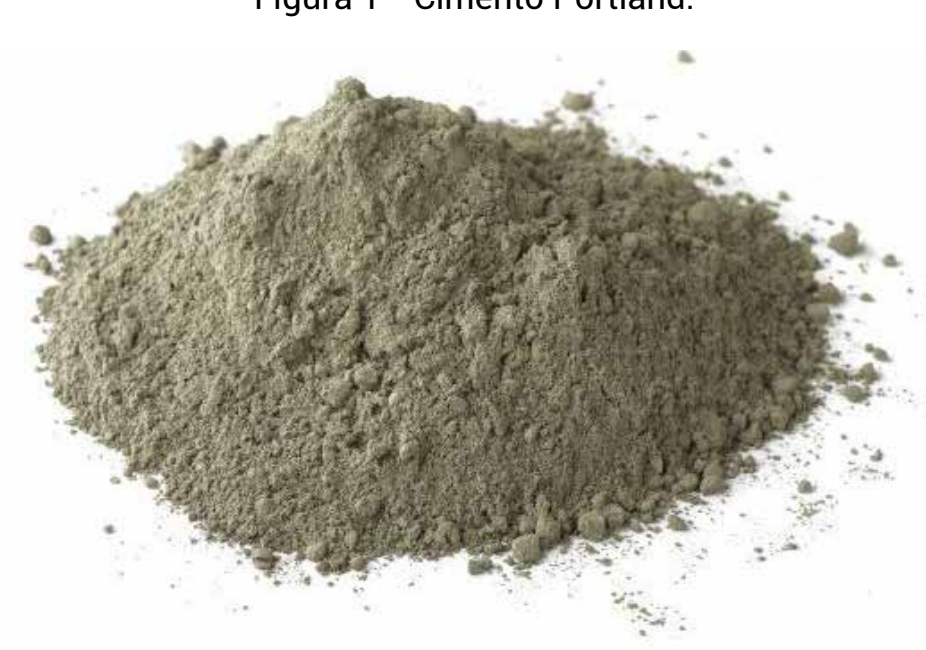

Fonte: dos autores.

2.1.2 Agregado graúdo (brita)

Para os ensaios foi utilizado agregado graúdo (brita um), conforme NBR 7211 (ABNT, 2009).

\subsubsection{Agregado alternativo (entulho)}

O entulho utilizado nestes ensaios visando proporcionar, é procedente de restos de obra de construção civil (RCD), neste caso, concreto de calçadas de um conjunto de prédios em Volta Redonda no estado do Rio de Janeiro.

Foi retirada uma amostra casual de resto de concreto em uma pilha de entulho da obra, a céu aberto, com idade superior a um mês.

Para o beneficiamento dos entulhos (resto de calçadas), as amostras coletadas foram trituradas e peneiradas, para que fosse possível obter os agregados na dimensão desejável.

Para os ensaios preliminares foi utilizado o entulho como brita um.

\subsubsection{Agregado miúdo (areia)}

O agregado miúdo (areia), com dimensão 0,063 a $2 \mathrm{~mm}$, utilizado na fabricação dos corpos de prova foi conforme NBR 9935 (ABNT,2011).

\subsection{4 Água}

A água usada na mistura da argamassa foi potável da rede de abastecimento da FOA e estava na temperatura de $(23 \pm 2)^{\circ} \mathrm{C}$.

\subsection{Moldagem e Cura}

A moldagem dos corpos-de-prova foi feita de acordo com a NBR 5.738 (ABNT, 2015). Como o procedimento do ensaio prevê a utilização de resto de concreto (entulho de obra) em proporções para a substituição da brita um de 0\%, 15\%,30\% e 100\%, conforme demonstrado na Tabela 1. 
Tabela 1 - Proporções de Adição de Entulho em Relação à Brita Um

\begin{tabular}{ccc}
\hline \% de entulho substituição da brita & Proporção cimento/areia/brita & $\mathbf{N}^{\circ}$ de corpos-de-prova \\
\hline 0 & $1: 2: 3$ & 3 \\
\hline 15 & $1: 2: 3$ & 3 \\
\hline 30 & $1: 2: 3$ & 3 \\
\hline 100 & $1: 2: 3$ & 3 \\
\hline
\end{tabular}

Fonte: dos autores.

No presente ensaio utilizou-se como parâmetro o mesmo procedimento do concreto, porém com o entulho de obra (concreto de calçadas) em substituição a brita um.

A cura dos corpos-de-prova, após sua moldagem, foi efetivada mediante à colocação dos mesmos em uma superfície horizontal rígida, livre de vibrações, protegidos de intempéries, durante $24 \mathrm{~h}$ com a finalidade de evitar perda de água. Em seguida foram identificados e levados a uma câmara úmida, onde ficaram armazenados até o momento do ensaio em uma solução saturada de hidróxido de cálcio a $\left(23 \pm 2^{\circ}\right)$ C, de acordo com a NBR 5.738 (ABNT, 2015).

As idades de cura definidas para os corpos-de-prova foram 7, 14, 21 e 28 dias.

\subsection{Procedimentos dos ensaios}

\subsubsection{Compressão}

O experimento foi executado, conforme a norma técnica NBR 5739 (ABNT, 2007), no que se refere a resistência à compressão de corpos-de-prova de concreto. Foram moldados corpos-de-prova cilíndricos com dimensões de 100×200mm, na proporção de três para cada adição e para cada idade.

Cada corpo-de-prova foi submetido a uma prensa hidráulica, conforme a Figura 2, de carga contínua até a ruptura do mesmo, na idade de 7, 14, 21 e 28 dias.

O resultado final foi a média dos três valores, em Mpa.

Figura 2 - Corpo de prova posicionado na máquina de ensaio após rompimento.

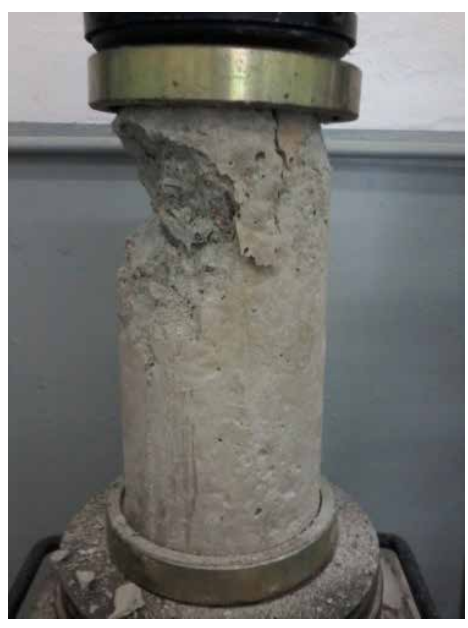

Fonte: dos autores. 


\subsubsection{Compressão diametral}

Este ensaio, segundo a norma NBR 7222 (ABNT, 1994), estabelece o método para determinação da resistência à tração por compressão diametral de corpos-de-prova cilíndricos de concreto.

Para este ensaio foram moldados os corpos- de-prova conforme norma NBR 5738 (ABNT, 2003). Foram confeccionados corpos-de-prova cilíndricos com dimensões $100 \times 200 \mathrm{~mm}$, em três unidades para cada adição e para uma idade. Cada corpo-de-prova foi submetido a uma prensa hidráulica (Figura 3) de carga contínua até a ruptura do mesmo, na idade de 28 dias. 0 resultado final da resistência à tração por compressão diametral foi calculado pela seguinte expressão:

$f_{t, D}=\frac{2 \cdot F}{d \cdot L \cdot \pi}$

Onde:

$f_{t, D}=$ resistência à tração por compressão diametral, expressa em MPa, com aproximação de 0,05 Mpa

$\mathrm{F}=$ carga máxima obtida no ensaio $(\mathrm{kN})$

$\mathrm{d}$ = diâmetro do corpo-de-prova $(\mathrm{mm})$

$\mathrm{L}=$ altura do corpo-de-prova $(\mathrm{mm})$

Figura 3 - Ensaio de compressão diametral corpo de prova posicionado após rompimento.

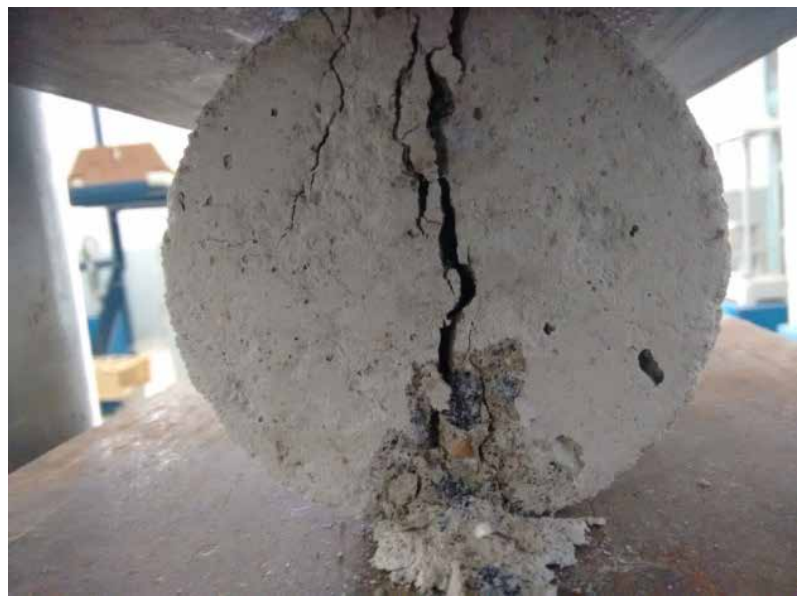

Fonte: dos autores.

\subsubsection{Microscopia (Análise da microestrutura do concreto com agregado reciclado)}

Para análise da microestrutura optou-se por fazer ensaios nas amostras de concreto de apenas uma idade de referência, já que o número de amostras para todo espaço amostral seria muito grande. A idade adotada foi de 28 dias, por ser um padrão normalmente adotado para todos os ensaios mecânicos em concreto. 
Adotou-se o percentual de $100 \%$ de substituição, do agregado graúdo pelo agregado reciclado graúdo. No que se refere à relação $\mathrm{a} / \mathrm{c}$, adotou-se o valor de 0,60 por ser este um valor usual para concretos com resistência média comumente utilizada em estruturas de concreto.

O concreto não é estruturado somente de cimento e agregados, mas também da zona de contato entre estes dois componentes (cimento e agregado). Esta zona de contato conhecida como interface pasta/agregado ou zona de transição aparece quando uma película de água se forma ao redor dos agregados durante o processo de exsudação de água no concreto, como mostra a Figura 4, o que aumenta a relação a/c desta área.

Devido a este aumento da relação a/c (água/cimento) os produtos cristalinos formados apresentam tamanho relativamente maior que os produtos existentes na matriz, o que torna a estrutura da interface mais porosa. Além de possuir maior dimensão, os produtos hidratados, principalmente os cristais de hidróxido de cálcio em formas de placas, tendem a se precipitar de forma orientada (MONTEIRO, 1993).

No concreto reciclado foram observadas a zona de transição entre os componentes do agregado reciclado - argamassas, ilustrado na Figura 5. As analises foram realizados no Centro Universitário de Volta Redonda UniFOA.

Os fragmentos dos corpos de prova recuperados do ensaio de resistência à compressão foram submetidos a um estudo de caracterização da microestrutura por meio da técnica de microscopia eletrônica de varredura.

Figura 4 - Vista geral da interfase pasta/agregado ampliado 18x.

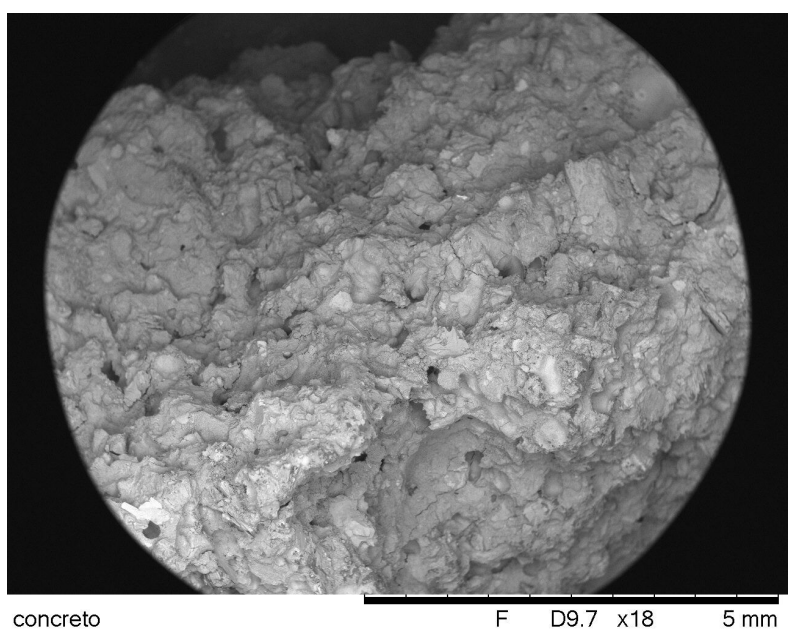

Fonte: dos autores. 
Figura 5 - Imagens do concreto com: (superior esquerda para direita) (a) amplitude 25x; (b) amplitude 40x; (c) amplitude 60x; (d) amplitude 100x; (e) amplitude 200x; (f) amplitude 250x; (g) amplitude 500x; (h) amplitude 1000x.
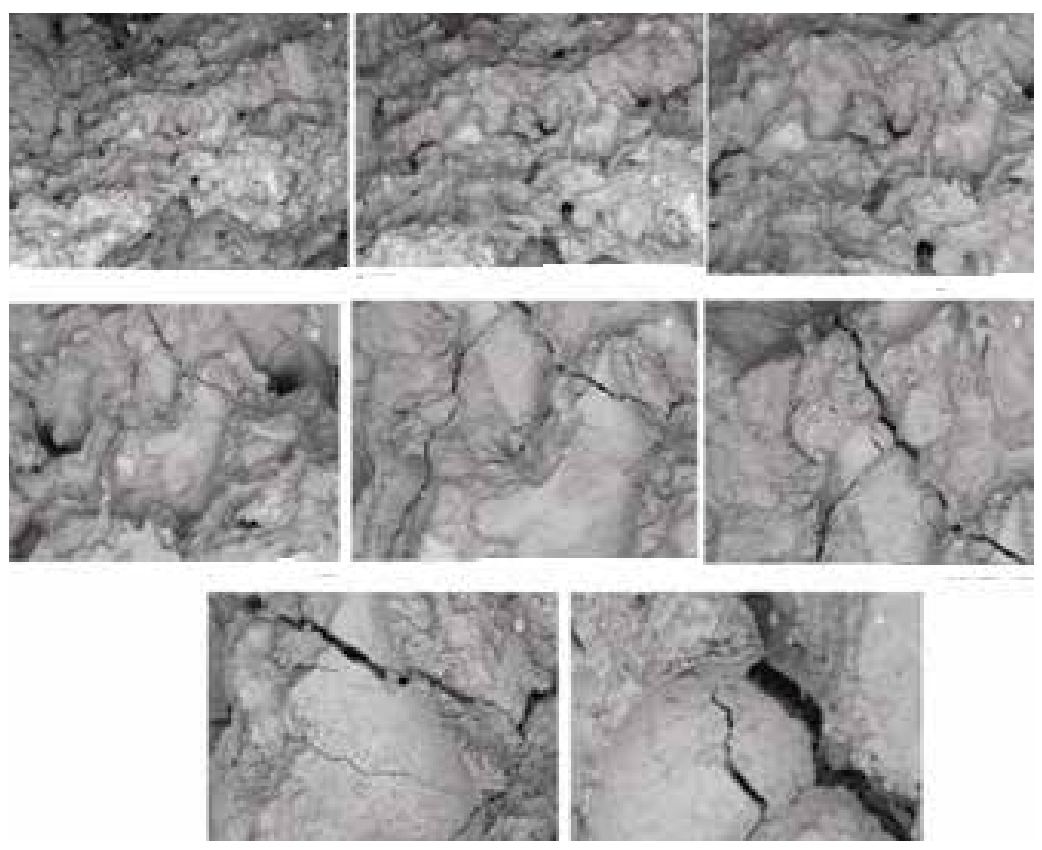

Fonte: dos autores.

\section{RESULTADOS E DISCUSSÃO}

A Figura 6 apresenta os resultados dos rompimentos dos corpos de prova por compressão simples.

A Tabela 2 apresenta os resultados por compressão diametral.

Figura 6 - Resultados das médias de compressão simples.

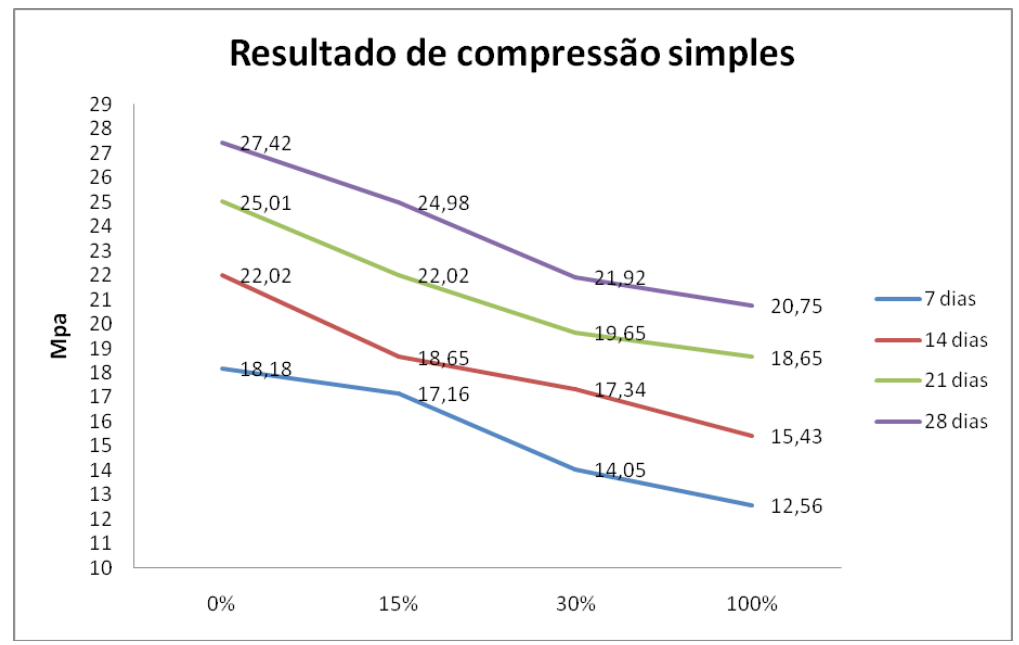

Porcentagem de entulho (\%)

Fonte: dos autores. 
Examinando o gráfico acima, percebe-se que há uma redução nos resultados da resistência à compressão simples, na proporção que se aumenta a porcentagem de entulho ao concreto, cerca de $1,87 \mathrm{Mpa}$ de média de $0 \%$ para $100 \%$ de adição de entulho na mistura do concreto aos sete (7) dias. 0 desvio padrão da amostra de $15 \%$ foi satisfatório em torno de 0,21 .

Com relação à diferença entre os valores obtidos em 15\% em relação a 0\% foi de 1,02 Mpa.

Houve queda de 3,11 Mpa nos corposdeprova de $30 \%$ em relação aos 15\% e em relação ao de $0 \%$ foi maior $4,13 \mathrm{Mpa}$.

Já os corpos de prova de 100\% de adição de entulho conforme houve uma diferença de 1,49 Mpa em relação aos corpos de $30 \%$.

Percebe-se que há uma redução nos resultados da resistência à compressão simples, na proporção que se aumenta a porcentagem de entulho ao concreto, cerca de 2,20 Mpa de média de $0 \%$ para $100 \%$ de adição de entulho na mistura do concreto aos quatorze (14) dias.

Com relação a diferença entre os valores obtidos em 15\% em relação a 0\% foi de 3,37 Mpa.

Houve queda de 1,31 Mpa nos corpos-de-prova de 30\% em relação ao 15\% e em relação ao de $0 \%$ foi maior 4,68 Mpa. Já os corpos-de-prova de 100\% de adição de entulho conforme houve uma diferença de 1,91 Mpa em relação aos corpos de $30 \%$.

Agora aos vinte e um dias, percebe-se que há uma redução nos resultados da resistência a compressão simples, na proporção que se aumenta a porcentagem de entulho ao concreto, cerca de 2,12 Mpa de média de $0 \%$ para $100 \%$ de adição de entulho na mistura do concreto.

Com relação a diferença entre os valores obtidos em 15\% em relação a 0\% foi de 2,37 Mpa.

Houve queda de 2,37 Mpa nos corpos-de-prova de $30 \%$ em relação ao 15\% e em relação ao de $0 \%$ foi maior $5,36 \mathrm{Mpa}$. Já os corpos-de-prova de $100 \%$ de adição de entulho conforme houve uma diferença de 1,00 Mpa em relação aos corpos de $30 \%$.

Com relação aos vinte e oito dias, percebe-se que há uma redução nos resultados da resistência a compressão simples, na proporção que se aumenta a porcentagem de entulho ao concreto, cerca de 2,22 Mpa de média de $0 \%$ para $100 \%$ de adição de entulho na mistura do concreto.

Com relação à diferença entre os valores obtidos em $15 \%$ em relação a $0 \%$ foi de $2,44 \mathrm{Mpa}$.

Houve queda de 3,06 Mpa nos corpos-de-prova de 30\% em relação ao 15\% e em relação ao de $0 \%$ foi maior $5,50 \mathrm{Mpa}$.

Já os corpos-de-prova de $100 \%$ de adição de entulho conforme houve uma diferença de 1,17 Mpa em relação aos corpos de $30 \%$.

Comparando as idades podemos observar que as amostras de 28 dias têm valores mais estáveis e maior valor de resistência que as amostras de 7, 14 e 21 dias e a variação de resistência é metade comparada à idade de 7 dias. 
Tabela 2 - Resultado de Compressão Diametral aos Vinte e oito Dias

\begin{tabular}{|c|c|c|c|c|c|c|c|}
\hline $\begin{array}{l}\text { Corpo de } \\
\text { prova }\end{array}$ & $\begin{array}{l}\text { Idade } \\
\text { (dias) }\end{array}$ & $\begin{array}{c}\% \text { de } \\
\text { entulho }\end{array}$ & $\begin{array}{l}\text { Relação } \\
\text { fração de areia } \\
\text { cimento }\end{array}$ & $\begin{array}{c}\text { Carga máxima } \\
\text { obtida no } \\
\text { ensaio (KN) }\end{array}$ & $\begin{array}{c}\text { Resistência } \\
\text { a tração por } \\
\text { compressão } \\
\text { diametral (MPa) } \\
\end{array}$ & $\begin{array}{l}\text { Média da } \\
\text { resistência } \\
(\mathrm{MPa})\end{array}$ & Desvio padrão \\
\hline 1 & 28 & 0 & $3 / 1$ & 66,89 & 2,13 & & \\
\hline 2 & 28 & 0 & $3 / 1$ & 69,48 & 2,22 & 2,24 & 0,12 \\
\hline 3 & 28 & 0 & $3 / 1$ & 74,33 & 2,37 & & \\
\hline 4 & 28 & 15 & $3 / 1$ & 67,27 & 2,14 & & \\
\hline 5 & 28 & 15 & $3 / 1$ & 68,32 & 2,17 & 2,02 & 0,23 \\
\hline 6 & 28 & 15 & $3 / 1$ & 55,17 & 1,76 & & \\
\hline 7 & 28 & 30 & $3 / 1$ & 65,56 & 2,09 & & \\
\hline 8 & 28 & 30 & $3 / 1$ & 66,69 & 2,12 & 2,05 & 0,10 \\
\hline 9 & 28 & 30 & $3 / 1$ & 60,69 & 1,93 & & \\
\hline 10 & 28 & 100 & $3 / 1$ & 48,31 & 1,54 & & \\
\hline 11 & 28 & 100 & $3 / 1$ & 42,21 & 1,34 & 1,42 & 0,11 \\
\hline 12 & 28 & 100 & $3 / 1$ & 42,46 & 1,35 & & \\
\hline
\end{tabular}

Fonte: dos autores.

Pelos resultados obtidos em ensaios de laboratório a resistência a compressão em corpos de prova de concreto, pôde-se observar que com adição de entulho (restos de calçadas) temos uma queda na resistência, mas com o passar do tempo (cura) como demonstra os resultados, os valores vão aumentando, mesmo com um percentual maior de entulho.

Observa-se uma queda nos resultados da resistência a compressão diametral com a adição de entulho. Entretanto os valores apresentado dentro de variações aceitáveis a sua aplicação na construção civil para fins não estrutural com porcentagem até $30 \%$ de adição de entulho, a partir daí a perda de resistência passa a ser significativo, fazendo com que o material proposto perca as características de aplicabilidade, conforme estudos já realizados indicam que a substituição de até $30 \%$ dos agregados graúdos naturais por agregado reciclado de resíduo de construção não altera significativamente as propriedades dos concretos produzidos, sendo esta, então, a forma mais simples e econômica de utilizar estes agregados (KIKUCHI ET AL.; KASHINO e TAKAHASHI; e YAMAMOTO, citados por LEVY, 1997).

\section{CONCLUSÃO}

A partir dos resultados encontrados, pode-se concluir que os resíduos de concreto possuem características apropriadas para serem reutilizados e reciclados, reduzindo os impactos ambientais e econômicos causados pelos índices de entulhos da construção civil.

Pelos resultados obtidos em ensaios de laboratório, no que tange à resistência à compressão em corpos-de-prova de concreto, pode-se observar que com adição de entulho temos uma queda na resistência, mas com o passar do tempo (cura), como demonstrado nos resultados, os valores vão aumentando, mesmo quando se usa um percentual maior de entulho.

Observa-se, também, uma queda nos resultados da resistência à compressão diametral com a adição de entulho. Entretanto, de acordo com os valores encontrados dentro de variações aceitáveis a 
aplicação de entulho na construção civil para fins não construtíveis, quando o percentual de adição de entulho atinge até $30 \%$ perde-se a capacidade de resistência de forma significativa.

Experimentalmente, foi comprovado através dos resultados obtidos que é possível utilizar a fração graúda do material reciclado ao desempenho mecânico do concreto. No entanto, compreende-se também, que apesar do bom comportamento apresentado, outros estudos devem ser realizados com o objetivo de confirmar os resultados obtidos no presente ensaio. Além disso, devem ser consideradas outras propriedades mecânicas como fluência e retração, bem como devem ser analisados os aspectos relativos à durabilidade das misturas de concreto.

Em síntese, o entulho obtido por meio de resíduos de concreto de calçadas, configura-se como uma alternativa para reciclagem, proporcionando a desoneração do meio-ambiente pela sua aplicação, inicialmente inservível, e que se mostrou com características de componente agregado na confecção de concreto para fins não estruturais.

\section{REFERÊNCIAS}

ABCP. Associação Brasileira De Cimento Portland. Guia básico de utilização do cimento portland. 7.ed. São Paulo, 2002. 24p. Disponível em: http://www.abcp.org.br/conteudo/wp-content/uploads/2009/12/BT106_2003.pdf. Acesso em: 14/03/2015.

ABNT. Associação Brasileira de Normas Técnicas. NBR 5.732 - Cimento Portlandcomum-especificação. Rio de Janeiro, 1991. 5p.

NBR 5.738 - Concreto: procedimento de moldagem e cura de corpos-de-prova. Rio de janeiro. 2008. 9p.

NBR 7.211 - Agregados para Concreto: especificação. Rio de Janeiro, 2009, 12p.

NBR 7.215 - Cimento Portland: determinação da resistência à compressão. Rio de Janeiro, 1996. 8p.

NBR 7.222 - Argamassa e concreto: determinação da resistência à tração por compressão diametral de corpos-de-prova cilíndricos. Rio de Janeiro, 1994.3p.

NBR 9.935 - Agregados: terminologia. Rio de Janeiro, 1987. 6p

ALBERTIN, R. M., MORAES, E.,NETO, G.A., DE ÂNGELIS, B.L.D., SCHMIDT, C. A. P., 2011. Avaliação da disposição final de resíduos sólidos urbanos no município de Cianorte, Paraná.

BAUER, L.A.F. Materiais de Construção. 5 ed. rev. Rio de Janeiro: LTC, 2011. p. 471.

BRASIL. Conselho Nacional do Meio Ambiente (CONAMA). Resolução nº 307, de 5 de julho de 2002. Estabelece diretrizes, critérios e procedimentos para a gestão dos resíduos da construção civil. s.l: 2002. 33-34p.

Resolução $n^{\circ}$ 348, de 16 de agosto de 2004. Altera a Resolução CONAMA n 307, de 5 de julho de 2002, incluindo o amianto na classe de resíduos perigosos.

BRASILEIRO, L.L.; MATOS, J.M. E. Revisão bibliográfica: reutilização de resíduos da construção e demolição na indústria da construção civil (Literature review: reuse of construction and demolition waste in the construction 
industry). Disponível em: http://www.scielo.br/pdf/ce/v61n358/0366-6913-ce-61-358-00178.pdf. Acessado 14/03/2015.

CARNEIRO, A.P.; BRUM, I. A.; COSTA. B. ET AL. Characterization of C\&D waste and processed debris aiming the production of construction materials. In: CIB SY MPOSIUM IN CONSTRUCTION AND ENVIRONMENT : THEORY INTO PRATICE, 2000, São Paulo, Brazil. Proccedings...\{CD-ROM]. São Paulo: CIB, 2000. 10p

ClOCCHI, L. Reciclagem de concreto. Revista Pini Web. 24/Setembro/2003. Disponível em: http://piniweb.pini.com. br/construcao/noticias/reciclagem-de-concreto-80112-1.aspx. Acesso em: 14/03/2015.

GALHARDO, P.G. Estudo do setor cimenteiro: produção e aplicação. Curso de Engenharia Civil. Projeto de Graduação. Rio de Janeiro: UFRJ, Escola Politécnica, 2014. Disponível em: http://monografias.poli.ufrj.br/monografias/ monopoli10012107.pdf.

LEVY, S.M. Reciclagem de entulho de construção civil para utilização como agregado de argamassas e concreto. p.145-147. Dissertação (Mestrado) - Escola Politécnica, Universidade de São Paulo, São Paulo, 1997.

MEHTA, P.K.; MONTEIRO, P.J.M. Concreto: microestrutura, propriedades dos materiais. 3. ed. São Paulo: IBRACON, 2008.

MONTEIRO, P.J.M. Caracterização da microestrutura do concreto: fases e interfaces; aspectos de durabilidade e de microfissuração. São Paulo, 1993. p.138. Tese (livre docência). Escola Politécnica da Universidade de São Paulo.

MOURÃO, C.A.M.A.; NOVAES, M.V.; KEMMER, S.L.; NUNES, F.R. M. Gestão de Fluxos Logísticos Internos na Construção Civil: o caso de obras verticais em Fortaleza-CE http://www.infohab.org.br/entac2014/2010/arquivos/322.pdf. 2010. Acesso em: 14/03/2015.

PETRUCCI, E.G. Concreto de Cimento Portland. São Paulo: Associação Brasileira de Cimento Portland, 1968.

PINTO, T.P. Metodologia para a gestão diferenciada de resíduos sólidos da construção urbana. p.189. Tese (Doutorado em Engenharia) - Escola Politécnica, Universidade de São Paulo, São Paulo, 1999.

PINHEIRO, L.M.; MUZARDO, C.D.; SANTOS, S.P. Estruturas de concreto. Cap. 1. USP. EESC. Dep. Eng. de Estruturas. Março de 2004. Disponível em: http://www.fec.unicamp.br/ almeida/ec702/EESC/introducao.pdf Acesso em: $11 / 03 / 2015$.

RILEM, T.C. 121-DRG. Specifications for concrete with recycled aggregates.Materials and Structures. V.27, p.557559. Publicações RILEM SARL,1994.

SINDUSCON-MG; SENAI-MG. Gerenciamento de Resíduos Sólidos da Construção Civil. Gerenciamento de Resíduos Sólidos da Construção Civil. $3^{\circ}$. Ed. Rev. e Aum. Belo Horizonte: SINDUSCON-MG, 2008. 72p. CDU: 628.544: 624 - CONSTRUÇÃO CIVIL - RESÍDUOS SÓLIDOS.

SINDUSCON-SP. Gestão Ambiental de Resíduos da Construção Civil: A experiência do SindusCon-SP. Tarcísio de P. Pinto - coordenador. São Paulo; Obra Limpa: I\&T: SindusCon-SP, 2005. (Publicação SinudCon-SP). 48 p. 